\title{
LAS REPRESENTACIONES SOCIALES DEL TRABAJO EN LAS COMUNIDADES INDÍGENAS MOCOVÍES, A PARTIR DE LA IMPLEMENTACIÓN DEL PROGRAMA DE EMPLEO DE INDUMENTARIA BÁSICA DE LA CIUDAD DE RECONQUISTA, SANTA FE
}




\section{INTRODUCCIÓN}

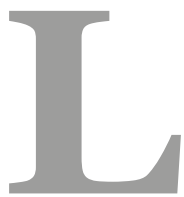

uego de la etapa de sometimiento militar y colonización de los grupos indígenas que poblaron el actual territorio argentino, el asalaramiento y la sedentarización fueron algunas estrategias implementadas para conjurar las prácticas autónomas de reproducción social como la "marisca" por parte de un Estado fuertemente centralizado basado en una concepción de unidad nacional tendiente a homogeneizar al territorio y a su población. Con estas estrategias, se pretendía integrar a los indígenas para utilizarlos de aporte de mano de obra; en principio fueron requeridos por la industria forestal como hacheros realizando tareas de baja calificación, poco después se añadieron a los ingenios azucareros y de cultivo de algodón. Cabe destacar que, para poder desarrollar ésta última actividad se necesitó mano de obra para ser concentrada estacionalmente llevando a cabo tareas de carpida y cosecha (Gómez, 2009).

El indígena fue incorporado a los circuitos productivos para la realización de las actividades que la sociedad occidental pretendía, lo que implicó la utilización de su mano de obra disponible para aquella. De esta manera, se fue perdiendo la importancia de las prácticas de reproducción social tradicional, lo cual significó enfrentarse a una realidad crítica, ya que el Estado trataba de fomentar su reconocimiento como individuo sujeto de derechos profundizando la negación de la diversidad cultural, alentando el "solapamiento" de una pertenencia identitaria étnica bajo las categorías de trabajador, productor, campesino, paisano.

A partir de la década de 1980, el retorno al sistema democrático significó para los indígenas de nuestro país la apertura de nuevas oportunidades políticas para la movilización y para una reformulación de la "cuestión indígena" bajo una modalidad que supuso una ruptura con las políticas indigenistas que prevalecieron durante el siglo XX. En este sentido, se produjo un cambio desde un "paradigma de la homogeneidad" (Quijada 2000) hacia una "puesta en valor de la diversidad cultural" (Briones, 2007). Las comunidades fueron reconocidas como sujetos colectivos de derecho, lo que dio lugar por primera vez a un trato no asimilacionista y respetuoso respecto de sus pautas de reproducción social. Sin embargo, en la actualidad la "marisca" y la fabricación de artesanías con la utilización de diferentes materias primas extraídas de la naturaleza, han dejado de considerarse como las principales actividades económicas destinada al sostén de las familias indígenas. Estas prácticas son realizadas a la par del asalaramiento o como complemento de prácticas agrícolas en muy pequeña escala. Esta situación evidencia que el trabajo en las comunidades indígenas ha cambiado debido a que el Estado actúa implementando políticas indigenistas mediante la formación para el trabajo con el objetivo de que cada familia pueda obtener su ingreso e insertarse en el mundo del empleo.

De allí radica el interés de esta investigación en abordar el significado del trabajo en las comunidades indígenas Mocovíes, considerando específicamente el programa de Indumenta-

${ }^{1}$ A. Paniagua, comunicación personal, 18 de Diciembre de 2014. 
ria Básica ${ }^{2}$ implementado en el año 2012 por la Secretaria de Desarrollo Social de la ciudad de Reconquista, como una nueva forma de trabajo.

A partir de lo expresado en los párrafos anteriores, los interrogantes que guían esta investigación son: ¿Cuáles son las representaciones sociales sobre el trabajo de los indígenas considerando el programa de empleo promovidos por el Estado?, ¿Qué actitud asumen los aborígenes frente a los programas de empleo implementados por el Estado?; ¿Cuáles son los programas que promueve el Estado en las Comunidades indígenas Mocovíes y qué representaciones recrean los indígenas respecto de los mismos?;¿Cuáles son los objetivos de los programas implementados por el Estado?, ¿Cómo define el Estado al indígena?; ¿Qué tiene en cuenta el Estado en el momento de implementar los programas de empleo?

Para obtener las respuestas de estos interrogantes, establecimos como objetivo general analizar las representaciones actuales en relación al trabajo en una comunidad indígena Mocoví de la ciudad de Reconquista, a partir de la implementación del programa de Empleo de Indumentaria Básica. Para ello nos propusimos caracterizar el programa de Indumentaria Básica implementado por el Estado y describir las representaciones sociales del trabajo de los indígenas Mocovíes.

\section{DISEÑO METODOLÓGICO}

En relación, a los métodos utilizados podemos decir que esta investigación es cualitativa, porque se basó en las perspectivas de los sujetos que protagonizan esta problemática, permitiendo conocer la subjetividad de los indígenas Mocovíes con respecto al Programa de Indumentaria Básica implementado desde la Secretaria de Desarrollo Social y Salud de la ciudad de Reconquista. Además, es un estudio descriptivo, ya que el mismo se basó en identificar los rasgos centrales que caracterizan al objeto de estudio.

Nuestras unidades de análisis fueron los hombres y las mujeres indígenas que estaban vinculados a los programas oficiales de empleo y que residían en la comunidad mocoví del Barrio la Lola, de Reconquista, provincia de Santa Fe.

\footnotetext{
${ }^{2}$ El Programa de Indumentaria Básica Protocolo 16 y 19 se implementó por la Gerencia de Empleo del Ministerio de Trabajo de la Nación, bajado éste por la Gerencia de Empleo de la provincia de Santa Fe, y a su vez ésta a la Gerencia de Empleo de la Municipalidad de la ciudad de Reconquista. Con ésta última gerencia, el Área de Economía Social, dependiente de la Secretaría de Desarrollo Social y Salud, trabaja de manera coordinada para la aplicación del mismo. Su finalidad es capacitar a las mujeres de la Comunidad Indígena Mocovíes para incluirlas en el Mercado de Trabajo.

Se dividió en dos niveles con su respectiva capacitadora. Uno consistió en brindar conocimientos básicos, y el otro nivel pretendia que las mujeres indígenas y no indígenas adquieran saberes específicos, como la utilización de máquinas industriales.

La duración de éste Programa fue de 3 (tres) meses por el transcurso de dos años, los días que se capacitaban eran los lunes, miércoles y viernes con 3 hs. (tres horas) cada día de 14 a 17, sumando un total de 9 (nueve) horas semanales. El Salón Comunitario era utilizado para realizar la capacitación. (V. Sponton, comunicación personal, Junio 24, 2014)
} 
A partir de allí, trabajamos con la población de hombres y mujeres indígenas de esa comunidad y realizamos un muestreo intencional. En ese sentido, consideramos dentro de la muestra a las mujeres perteneciente a la comunidad indígena Mocoví que se encontraban capacitando a través del Programa Indumentaria Básica implementado por la Secretaría de Desarrollo Social y Salud. Asimismo, entrevistamos a funcionarios municipales pertenecientes al área de Economía Social de la Secretaría de Desarrollo Social y Salud. Entre ellos, cabe destacar a René López, quien además es miembro de la comunidad.

Trabajamos con datos primarios construidos a partir de entrevistas no estructuradas focalizadas e individuales con preguntas abiertas realizadas a las mujeres indígenas Mocovíes, a las Funcionarias de la Secretaria de Desarrollo Social y Salud de la ciudad de Reconquista y al Referente respectivo de la Comunidad Indígena. Además, se trabajó con datos secundarios como ser libros, archivos, documentos bibliográficos existentes en las diversas redes sociales, registros de las personas que se encontraban realizando las capacitaciones brindadas por el Área de Economía Social de la Secretaría de Desarrollo Social y Salud situada en la ciudad de Reconquista.

\section{AVANCES DE LA INVESTIGACIÓN}

Si bien esta investigación aún se encuentra en desarrollo, a continuación se presentan algunos avances preliminares que permiten avanzar con respuestas parciales a los interrogantes asumidos inicialmente.

En relación, a las transformaciones en el trabajo podemos decir que la gran mayoría de las mujeres se dedica a realizar actividades en su respectivo hogar, recibiendo el ingreso económico de la Asignación Universal por hijo; mientras que los hombres realizan actividades temporarias, esporádicas como albañilería, ladrillería. Estas actividades se diferencian de las prácticas tradicionales que remiten a actividades vinculadas con la naturaleza, como cazar, pescar, o recolectar frutos, en el caso de las mujeres. No obstante, cabe señalar que aunque solo una de las personas entrevistadas posee un empleo asalariado estable como docente bilingüe, esa actividad se complementa con la fabricación de artesanías. En ese caso pudimos identificar prácticas vinculadas a la recreación de una identidad cultural y a la continuidad de pautas tradicionales, aún cuando existe una integración al mercado de trabajo. Se asume que la cultura va trascendiendo en el tiempo en los miembros de la familia porque él es quién enseña a sus hijos mayores a fabricar las mismas, para que aquellos transmitan ese conocimiento.

Respecto de las representaciones en torno al trabajo, podemos decir que algunas personas tienen una perspectiva vinculada al aspecto económico, es decir, trabajan para obtener dinero y con éste adquirir algún bien material. Esto le permitiría crecer económicamente.

Otra de las personas, específicamente una de las jóvenes entrevistadas considera que 
mediante el trabajo se puede independizar de su familia.

También, existen otras personas que relacionan el trabajo con el aspecto educación. Ellas expresan que mediante el trabajo se adquieren conocimientos, los cuales les permiten el desarrollo de su actividad laboral.

Cabe destacar, que la gran mayoría de las personas indígenas presentan perspectivas vinculadas al tiempo presente, sólo una de las familias entrevistadas tiene expectativas para un periodo futuro; se puede ejemplificar con uno de los hijos ya que sus padres le dieron la oportunidad de estudiar para llegar a ser un Agente de policía, lo que implicó adquirir conocimientos, para obtener un trabajo estable y lograr así un mejor bienestar para su familia en un periodo lejano.

Además, decimos que en la gran mayoría de las familias observamos que niños y jóvenes le otorgan gran importancia o pertinencia a la educación; situación adversa se presenta en las personas adultas (específicamente en los hijos/as) por no culminar con sus estudios secundarios. Esto se debe a diversas razones por constituir una familia, por no considerar que finalizar los estudios primarios y secundarios permite acceder a un puesto de trabajo. Nuevamente, expresamos que en estas personas no existen perspectivas relacionadas a un periodo futuro, perspectivas de progreso, o de crecimiento económico, personal, profesional.

En relación, a las políticas de empleo existen diversas perspectivas. La gran mayoría de las mujeres consideran que el programa de indumentaria es una oportunidad, ya que les permite adquirir conocimientos e insertarse así en el mercado de trabajo; mientras que existen otras mujeres que sostienen que capacitarse con el programa de Indumentaria les permite compartir momentos de alegría, de amistad con sus pares y su instructora.

A modo de cierre, decimos que en la realidad que vivimos existe un solapamiento de los paradigmas de la Homogeneidad y Diversidad Cultural, porque considerando el primero, la gran mayoría de indígenas mocovíes, y algunas de las mujeres realizan actividades como fabricación de productos artesanales, fabricación de ladrillos para comercializarlos en la ciudad de Reconquista; actividades totalmente diferentes a las tradicionales, requeridas por la sociedad mayoritaria. En los hombres ocurre lo mismo, ya que se dedican a actividades esporádicas o temporarias vinculadas con la molición de maíz, ladrillería, o albañilería.

En contraposición a este paradigma, se encuentra una mujer adulta de 70 años de edad, acompañada de sus hijas expresa su pedido respecto de capacitarse en temas vinculados a la confección de prendas, una actividad típica que fue llevada a cabo en un periodo pasado. También, se presenta una situación similar con un hombre de 51 años de edad, éste transmite a sus hijos sus saberes vinculados a la fabricación de artesanías.

Esto nos lleva a decir que, en estas personas adultas y en sus respectivas familias existe aún un apego de sus padres hacia sus hijos e inversamente, y a su vez, por sus prácticas tradicionales, lo cual implica que la cultura se va trasmitiendo de generación en generación respecto del modo de hacer el trabajo; situación o realidad adversa a la gran mayoría de indígenas pertenecientes a la comunidad. Esto se refleja en una realidad expresada por aquel hombre: 
“...Los jóvenes están más con los padres, esto viene de una cultura también. Viene de una cultura más ante tiempo vivían todos juntos. Hay una generación y a veces no se puede salir de esa generación, este uno muere, si ese muere queda nieto o hijo, viene de ramas, viene de siglos. Es una rama no puede no se puede quebrarse, es una rama que viene de arriba...”’

\section{REFERENCIAS BIBLIOGRÁFICAS}

Briones, C. (2007) "La puesta en valor de la diversidad cultural: implicancias y efectos". En Revista Educación y Pedagogía. Vol. XIX, Núm. 48 (mayo-agosto), Medellín: Universidad de Antioquia-Facultad de Educación.

Gómez, C. (2009) "Mariscan en todos lados. La idiosincrasia indígena y las perversiones del esencialismo estratégico", en Suplemento Antropológico, Vol. XLIV, $\mathrm{N}^{\circ} 2$, pp. 557-590.

Gómez, C. y Hadad, M. Gisela (2009). Manifestación de la emergencia indígena Argentina. Trabajo presentado en el XXVII Congreso de la Asociación Latinoamericana de Sociología. Asociación Latinoamericana de Sociología, Buenos Aires.

Jodelet, D. \& Moscovici, S. (1986). Psicología Social II. Ediciones Paidos. Barcelona-Buenos Aires: (s. n).

Quijada, Mónica (2000) “El paradigma de la homogeneidad”, en Quijada, Mónica; Bernand, Carmen y Schneider, Arnd. Homogeneidad y nación con un estudio de caso: Argentina siglos XIX y XX. Madrid: Consejo Superior de Investigaciones Científicas. Centro de Humanidades. Instituto de Historia. 


\section{CURRICULUM VITAE}

\section{César A. Gómez}

Magister en Investigación en Ciencias Sociales. Profesor Adjunto ordinario de la asignatura Sociología General de la Licenciatura en Relaciones Laborales (FCE-UNNE).

cesarabelgomez@gmail.com

\section{Fabiana Pereson}

Estudiante avanzada de la Licenciatura en Relaciones Laborales (FCE-UNNE).

fabiana.pereson@hotmail.com 